Article

\title{
Transformation of Cyclaneusma minus with Green Fluorescent Protein (GFP) to Enable Screening of Fungi for Biocontrol Activity
}

\author{
Rebecca McDougal $^{1, \dagger}{ }^{\dagger}$, Alison Stewart ${ }^{2}$ and Rosie Bradshaw ${ }^{1}$ \\ 1 Institute of Molecular BioSciences, College of Sciences, Massey University, Private Bag 11-222, \\ Palmerston North, 4442, New Zealand; E-Mail: r.e.bradshaw@massey.ac.nz \\ 2 Bio-Protection Research Centre, P.O. Box 84, Lincoln University, Christchurch 7647, New Zealand; \\ E-Mail: alison.stewart@lincoln.ac.nz \\ $\dagger$ Current Address: Scion, New Zealand Forest Research Institute Ltd., Private Bag 3020, Rotorua, \\ 3046, New Zealand.
}

* Author to whom correspondence should be addressed; E-Mail: rebecca.mcdougal@scionresearch.com; Tel.: +647-343-5534; Fax: +647-348-0952.

Received: 23 November 2011; in revised form: 10 January 2012 / Accepted: 19 January 2012 / Published: 1 February 2012

\begin{abstract}
Cyclaneusma needle-cast has a major impact on the New Zealand forest industry. The causal agent, Cyclaneusma minus, causes most severe damage to 11-20 year-old trees and currently there are no economically viable procedures for control of the disease in New Zealand. Here we present a method for genetic transformation of $C$. minus using protoplasts generated by incubation with Glucanex ${ }^{\mathrm{TM}}$ enzyme. C. minus was transformed with a gene encoding green fluorescent protein (GFP) and expression was stable after successive sub-culturing of the strain in the absence of selective pressure. Expression of the gfp gene allowed us to utilize an in vitro GFP-based screening method to identify strains of Trichoderma with potential for biocontrol of this disease. The strain that showed the most promise as a potential biocontrol candidate exhibited a low level of inhibition by uncharacterized metabolite(s) that C. minus secretes into the medium, and consistently caused a loss of GFP expression from the GFP-labeled C. minus strain. The interaction between $C$. minus and the biocontrol strain, in the interaction zone where GFP expression was lost, was determined to be fungicidal. The utility of such biocontrol strains is discussed. This study represents the first genetic manipulation of $C$. minus and will pave the way for further studies of the life cycle and infection biology of this organism.
\end{abstract}


Keywords: Cyclaneusma; needle-cast; protoplast; transformation; antagonism; biocontrol; GFP

\section{Introduction}

Cyclaneusma minus (Butin) DiCosmo, Peredo and Minter [1] is an ascomycetous fungus associated with disease in Pinus spp. Like many fungi, Cyclaneusma has undergone name changes during its research history and this has been documented elsewhere [2,3]. In addition, taxonomic classification of Cyclaneusma and Naemacyclus has been ambiguous [4]. Recent phylogenetic analysis has suggested that Cyclaneusma and Naemacyclus be treated as Leotiomycetes incertae sedis [5].

C. minus causes needle-cast in Pinus species worldwide, such as in Christmas tree plantations (P. sylvestris L.) [6,7]. Its association with disease is complicated by the fact that it can be found in asymptomatic tissue, and hence is often regarded as an endophyte or latent pathogen [8-10]. In Europe, Cyclaneusma minus is frequently reported as an endophyte. It has been recently isolated in Estonia although it is not acting as a serious pathogen [11]. In South Africa C. minus occurs mainly as a saprophyte on dead needles and is not associated with disease symptoms [12]. C. minus infects many Pinus species including $P$. radiata D. Don which is the predominant plantation species in New Zealand. Cyclaneusma needle-cast (CNC) currently causes the greatest economic loss compared to any other disease in the $P$. radiata plantation industry in New Zealand, costing \$38 million each year [13].

$\mathrm{CNC}$ is most severe in $P$. radiata plantations with trees aged 11 to 20 years old, in New Zealand, although infection with $C$. minus is observed in trees from age three years [2]. Early observations showed a predominance of severe infections in isolated trees in a stand [14], as opposed to a part of a stand or a whole stand being infected. But more recently the disease has presented as mild infection in part of the stand or the whole stand, with individually infected trees observed less often [15]. This change in disease pattern has been attributed to the elimination of highly susceptible tree genotypes from planting stock in New Zealand [13]. Until recently the species of Cyclaneusma present in New Zealand were reported be C. niveum and C. minus [3]. C. minus has also been shown to consist of the "verum" and "simile" varieties [16], although recent research has suggested that these two varieties are actually separate species [17]. There is an urgent need for more detailed studies of the genetics, epidemiology and infection biology of this pathogen. Development of a genetic transformation system for C. minus would provide a useful tool to facilitate these studies. For example the use of reporter genes such as the green fluorescent protein $(g f p)$ gene has become a popular method for monitoring fungal interactions $[18,19]$. GFP-labeling has been used to observe interactions of fungi with their plant hosts or with other fungi $[20,21]$. Therefore, GFP-labeling could provide a useful tool for studies of C. minus infection biology.

Several options for control of CNC have been investigated. In New Zealand, planting of tree genotypes less susceptible to disease during the 1990s has resulted in reduced levels of infection compared to those planted in the 1970s [22]. Genetic resistance has also been observed in P. sylvestris [7]. Silvicultural trials showed that stocking density and pruning had no effect on disease, although delayed thinning did provide control of CNC [2]. Fungicide trials performed in the 1980s 
achieved reductions in infection levels, but not at a level where the cost of spraying could be justified [23], hence fungicide treatment is not a viable option for control. It has been shown by modeling that CNC disease severity is sensitive to environmental conditions. This information will provide a baseline to predict the impact of CNC under future climate scenarios [24].

Research into biocontrol for diseases of pine has gained momentum in recent times, including studies of biocontrol for nursery diseases [25,26], wood stain fungi [27,28] and wood decay [29]. Trichoderma species have been investigated for control of Phythophthora cinnamomi Rands in $P$. radiata roots [25] and for enhancing induced resistance to infection by Diplodia pinea (Desm.) Kickx [30]. Biocontrol has also been successfully used for control of Armillaria-induced P. radiata seedling mortality with a formulation of Trichoderma spores (ArborGuard ${ }^{\mathrm{TM}}$ ) [31-33]. A recent study has also investigated the potential for Trichoderma and Clonostachys species to control Fusarium circinatum Nirenberg and O'Donnell, the causal agent of pitch canker [34].

The use of biocontrol for Dothistroma septosporum (Dorog.) Morelet, another fungal pathogen of $P$. radiata, has been previously studied [35]. Screening of various fungal and bacterial strains using a novel method with green fluorescent protein (GFP)-labeled D. septosporum revealed several biocontrol strains with potential for use in control of dothistroma needle blight (DNB). This screening method uses GFP as an indicator of metabolic activity in the pathogen and also utilizes the hygromycin resistance selection marker (also encoded by the plasmid containing the gfp gene) to determine if the interaction is fungicidal or fungistatic. This method also takes into account the effect of inhibitory metabolites, produced by the pathogen, on the biocontrol strains [35]. The ability of biocontrol strains to provide control for $\mathrm{CNC}$, as well as $\mathrm{DNB}$, would present a unique opportunity for dual disease control for the forestry industry in New Zealand, especially considering no other means of control currently exist for CNC.

The aims of this work were, firstly, to develop a transformation system for C. minus, using the green fluorescent protein ( $g f p$ ) gene and, secondly, to use the C. minus gfp transformant to determine if strains of Trichoderma spp. shown to be antagonistic to another foliar pine pathogen, $D$. septosporum, are also antagonistic to C. minus.

\section{Materials and Methods}

\subsection{Source and Maintenance of Fungal Cultures}

Cyclaneusma minus strain NZFS3617 was isolated from a symptomatic Pinus radiata tree in Kaingaroa Forest, New Zealand (Margaret Dick, Scion, Rotorua, New Zealand). All Trichoderma strains tested as potential biocontrol candidate strains were obtained from the Bio-Protection Research Centre, Lincoln University, New Zealand. Dothistroma septosporum strain FJT20 [35] was utilized as a positive control in some experiments as it has been previously transformed with the gfp gene. E. coli strain XL1-Blue [36] was used for plasmid propagation.

Dothistroma cultures were routinely maintained on dothistroma medium (DM) [37]. C. minus and Trichoderma strains were maintained on potato dextrose agar (PDA; Merck, Dramstadt, Germany). E. coli strain XL-1 was maintained on Luria-Bertani (LB) medium [38]. Pine minimal medium with glucose (PMMG) was used as an alternative medium to PDA for growth experiments and competition 
assays [35]. All fungal culture incubations were performed at $22{ }^{\circ} \mathrm{C}$, and E. coli incubations were performed at $37^{\circ} \mathrm{C}$.

\subsection{Plasmid and Propagation}

Plasmid pCT74, containing the gfp gene, has been described previously [18]. The plasmid was propagated by growth in E. coli XL-1 and extracted using an alkaline lysis method [38]. Plasmid DNA was restriction digested with SalI to confirm the correct size and quantified using a Nanodrop-1000 spectrophotometer (Thermo-Fischer Scientific, Waltham, MA, USA).

\subsection{Protoplast Preparation and Transformation of C. minus}

Protoplast generation and transformation were performed using a method based on that of Bradshaw et al. [39]. Ground mycelium of C. minus was inoculated onto PDA medium overlaid with sterile cellophane, and incubated at $22{ }^{\circ} \mathrm{C}$ for 6 days. Cellophanes with C. minus growth were removed from the agar and incubated with a sterile Glucanex ${ }^{\mathrm{TM}}$ (Novozymes Corp., Bagsværd, Denmark) solution $\left(20 \mathrm{mg} \cdot \mathrm{mL}^{-1}\right.$ in $\mathrm{OM}$ buffer; $1.4 \mathrm{M} \mathrm{MgSO}_{4}, 10 \mathrm{mM} \mathrm{Na} \mathrm{HPO}_{4}$, pH adjusted to 5.8 with $100 \mathrm{mM} \mathrm{NaH}_{2} \mathrm{PO}_{4}$ ) at $30{ }^{\circ} \mathrm{C}$ with shaking at $110 \mathrm{rpm}$, for approximately $18 \mathrm{~h}$. Protoplasts were placed into Corex centrifuge tubes in $5 \mathrm{~mL}$ aliquots and overlaid with $2 \mathrm{~mL}$ of ST buffer $(0.6 \mathrm{M}$ sorbitol, $100 \mathrm{~mm}$ Tris- $\mathrm{HCl} \mathrm{pH} 8.0$ ). Following centrifugation for $5 \mathrm{~min}$ at $20^{\circ} \mathrm{C}$ and $1085 \times \mathrm{g}$, protoplasts were collected from the interface and washed twice with $5 \mathrm{~mL}$ of STC buffer $\left(1 \mathrm{M}\right.$ sorbitol, $50 \mathrm{~mm} \mathrm{CaCl}_{2}$, $50 \mathrm{~mm}$ Tris- $\mathrm{HCl} \mathrm{pH} \mathrm{8.0)} \mathrm{with} \mathrm{further} \mathrm{centrifugation} \mathrm{for} 5 \mathrm{~min}$ at $20{ }^{\circ} \mathrm{C}$ and $1085 \times \mathrm{g}$. The protoplasts were resuspended in STC buffer at a concentration of $10^{7}-10^{8}$ per $\mathrm{mL}$. Twenty $\mu \mathrm{L}$ of polyethylene glycol (PEG) 6000 solution (40\% w/v PEG, $1 \mathrm{M}$ sorbitol, $50 \mathrm{mM} \mathrm{CaCl}_{2}, 50 \mathrm{mM}$ Tris-HCl, pH 8.0) was added to $80 \mu \mathrm{L}$ aliquot of protoplasts. Approximately $2.5 \mu \mathrm{g}$ of pCT74 DNA was added to the protoplasts, mixed gently and incubated on ice for $30 \mathrm{~min}$. Additional PEG solution $(900 \mu \mathrm{L})$ was added and protoplasts were mixed gently and incubated at $20{ }^{\circ} \mathrm{C}$ for $20 \mathrm{~min}$. Aliquots $(100 \mu \mathrm{L})$ were added to sterile, molten, non-selective medium (potato dextrose broth [PDB] containing $0.8 \mathrm{M}$ sucrose and $0.8 \%[\mathrm{w} / \mathrm{v}]$ agar) and poured over base agar (PDB containing $0.8 \mathrm{M}$ sucrose and $1.5 \%$ [w/v] agar). Plates were incubated at $22{ }^{\circ} \mathrm{C}$ overnight. Selective overlay medium containing hygromycin B $(100 \mu \mathrm{g} / \mathrm{mL})$ was prepared and poured over the plates. Incubation was continued at $22{ }^{\circ} \mathrm{C}$.

\subsection{DNA Extraction}

The wild-type strain and a putative transformant of C. minus were grown in PDB for eight days with shaking at $200 \mathrm{rpm}$. D. septosporum strain FJT20 was grown in DM broth for seven days with shaking at $200 \mathrm{rpm}$. Mycelia were harvested by centrifugation at $4000 \mathrm{rpm}$ for $10 \mathrm{~min}$ (Eppendorf centrifuge 5810) and stored at $-20{ }^{\circ} \mathrm{C}$ prior to freeze-drying. DNA was extracted using a previously described method [40]. DNA was further purified using a Perfect Prep Gel Cleanup column (Eppendorf, Hamburg, Germany) starting from step five of the manufacturer's instructions. DNA was eluted in $60 \mu \mathrm{L}$ of sterile milliQ water and quantified using a Nanodrop-1000 spectrophotometer (Thermo-Fischer Scientific, Waltham, MA, USA). 


\subsection{PCR Amplification of the gfp Gene from the Transformant}

To confirm the presence of the $g f p$ gene in putative transformants, DNA was amplified using primers rtGFPfwd1 and rtGFPrev1 [35]. DNA from wild-type C. minus and D. septosporum FJT20 were used as negative and positive controls respectively, as well as a no-template control to check for contamination. PCR reactions were performed using the FIREPol ${ }^{\circledR}$ DNA Polymerase kit (Solis BioDyne, Tartu, Estonia), according to the manufacturer's instructions. Each $25 \mu \mathrm{L}$ PCR reaction typically contained $10 \times$ buffer BD $(2.5 \mu \mathrm{L}), 1.5 \mathrm{mM} \mathrm{MgCl}_{2}, 0.4 \mu \mathrm{M}$ of each primer, $1.25 \mathrm{U}$ of FIREPol ${ }^{\circledR}$ DNA Polymerase, $1 \mu \mathrm{L}$ of DNA (approx $50 \mathrm{ng}$ ) and PCR-grade water (up to $25 \mu \mathrm{L}$ total volume). The cycling conditions consisted of an initial denaturation step of $95{ }^{\circ} \mathrm{C}$ for $4 \mathrm{~min}$, then 30 cycles of $94{ }^{\circ} \mathrm{C}(1 \mathrm{~min}), 55{ }^{\circ} \mathrm{C}(1 \mathrm{~min})$ and $72{ }^{\circ} \mathrm{C}(1 \mathrm{~min})$, and a final extension step of $72{ }^{\circ} \mathrm{C}(10 \mathrm{~min})$. Gel electrophoresis was performed with $1 \%$ (wt/vol) agarose in TBE and visualized by UV transillumination after staining with ethidium bromide.

\subsection{Southern Hybridization}

For hybridization, digested genomic DNA from wild-type and putative transformant strains, as well as D. septsporum FJT20 was transferred to Amersham Hybond- $\mathrm{N}^{+}$nylon membranes (GE Healthcare Ltd., Buckinghamshire, UK) by capillary transfer [38]. A gfp gene probe was labelled using a DIG high-prime DNA labelling system (Roche Applied Science, Penzberg, Germany). Hybridizations were carried out at $42{ }^{\circ} \mathrm{C}$ in Roche standard hybridization buffer containing formamide [50\% deionized formamide, $5 \times \mathrm{SSC}, 0.1 \%(\mathrm{w} / \mathrm{v}) \mathrm{N}$-lauroylsarcosine, $0.02 \%(\mathrm{w} / \mathrm{v}) \mathrm{SDS}$, and $2 \%(\mathrm{w} / \mathrm{v})$ blocking reagent].

\subsection{Comparison of Growth Rates}

Growth of the C. minus wild-type and the confirmed transformant were compared on PDA and PMMG ( $\mathrm{pH} 4.0$ and 7.0) to determine if transformation of C. minus with the gfp gene had any detrimental effects on growth. A $6 \mathrm{~mm}$ mycelial plug was inoculated onto each medium for both strains. Plates were prepared in triplicate and incubated at $22{ }^{\circ} \mathrm{C}$. Growth measurements were performed at time intervals over 20 days. Data were analyzed in Microsoft Excel; a TTEST was used to determine if there was significant difference in growth rates between the strains.

\subsection{Screening Potential Biocontrol Strains}

Competition assays were performed with gfp-labeled C. minus (FJT95) as described by McDougal et al. [35], on both PDA and PMMG medium, except that the gfp-labeled C. minus strain was incubated for nine days prior to co-inoculation with biocontrol strains. For assessment of fungicidal or fungistatic effects, plugs were cut from colonies of FJT95 on the biocontrol challenge plates that had completely lost GFP fluorescence. These were then sub-cultured onto PDA medium, containing hygromycin $\mathrm{B}$ at pre-determined minimum inhibitory concentrations (MIC) ranging from $100-180 \mu \mathrm{g} \cdot \mathrm{mL}^{-1}$. 


\section{Results}

\subsection{C. minus Protoplast and Transformation Yield, and GFP Expression}

Approximately $6 \times 10^{8}$ protoplasts were obtained from mycelium grown on four cellophane discs. A higher yield of protoplasts was obtained after $24 \mathrm{~h}$ incubation with Glucanex ${ }^{\mathrm{TM}}$ compared to $8 \mathrm{~h}$ incubation (data not shown). Growth of mycelia and regeneration of protoplasts of untransformed C. minus (no DNA control) were completely inhibited by $100 \mu \mathrm{g} / \mathrm{mL}$ hygromycin B. Transformation efficiency was very low with only four putative transformant colonies observed on selective medium. GFP was present in one colony (out of four) when observed under UV light, indicating that the $g f p$ gene was expressed in one transformant. GFP expression was absent in the $C$. minus wild-type strain. The GFP expression was determined to be stable in the transformant by successive sub-culturing, on non-selective medium, without loss of GFP. The C. minus gfp transformant was designated FJT95.

\subsection{Molecular Characterization of FJT95}

DNA yields were high (average $0.7 \mu \mathrm{g}^{\mathrm{DNA} \mathrm{mg}}{ }^{-1}$ dry weight of mycelium) from C. minus FJT95, C. minus wild-type (untransformed) and D. septosporum FJT20. PCR was performed to determine the presence of the $g f p$ gene using rtGFPfwd1 and rtGFPrev1 primers with DNA from C. minus FJT95. PCR products of the expected size (approximately $450 \mathrm{bp}$ ) were obtained with DNA from C. minus FJT95 and the positive control strain D. septosporum FJT20, but no products were obtained with DNA from C. minus wild-type or in the no-template control (Figure 1).

Figure 1. Detection of $g f p$ gene by PCR in C. minus transformant strain FJT95. Lane 1, $1 \mathrm{~kb}^{+}$ladder; Lane 2, C. minus FJT95; Lane 3, C. minus wild-type; Lane 4, D. septosporum strain FJT20; Lane 5, no-template control.

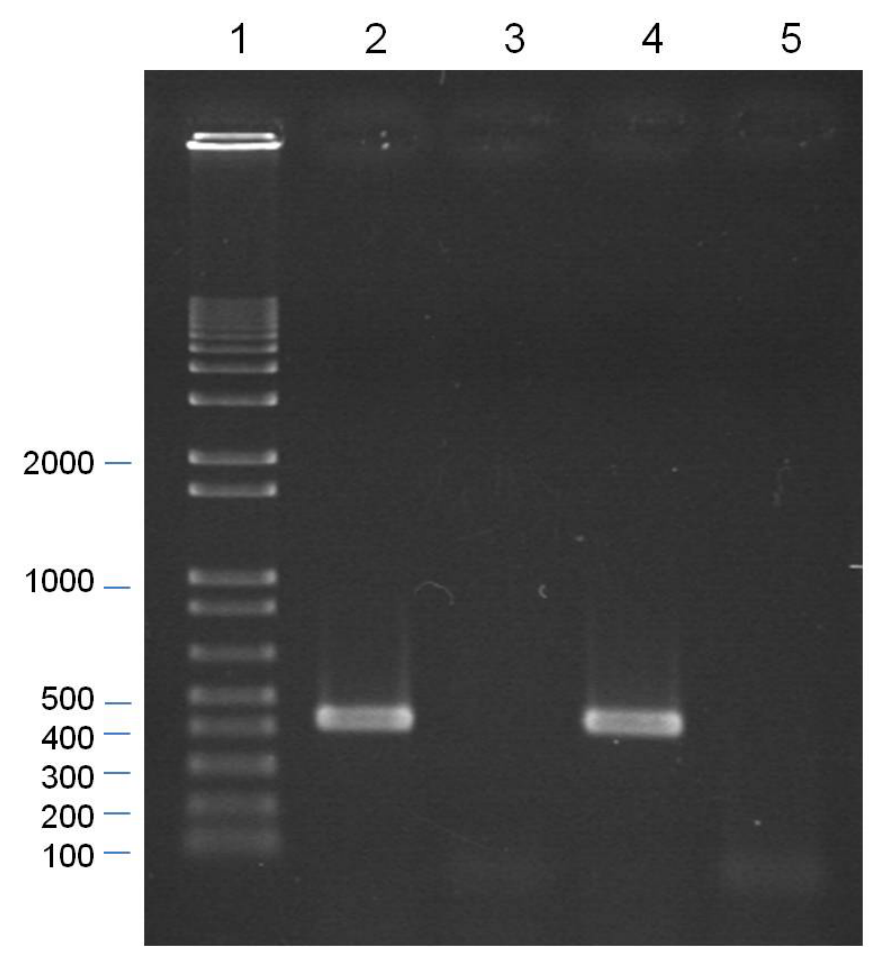


The presence of the $g f p$ gene in strain FJT95 was verified by Southern hybridization. The $g f p$ probe hybridized to DNA fragments of approximately $7.5 \mathrm{~kb}$ in the C. minus FJT95 transformant and a DNA fragments of approximately $8.0 \mathrm{~kb}$ in D. septosporum FJT20 (positive control), but no hybridization was observed to DNA from C. minus wild-type (data not shown).

\subsection{Growth of FJT95 Compared to C. minus Wild Type}

To determine whether transformation of C. minus with pCT74 had an effect on the growth of FJT95, strains were grown on PDA and PMMG medium and growth rates were determined over time. No significant difference $(p>0.05)$ was observed in the growth rates of the FJT95 transformant compared to $C$. minus wild-type on PDA or PMMG medium: FJT95 exhibited a growth rate of $1.4 \pm 0.1 \mathrm{~mm} \cdot \mathrm{day}^{-1}$ on PDA and $1.6 \pm 0.0 \mathrm{~mm} \cdot \mathrm{day}^{-1}$ on PMMG medium, whereas the C. minus wild-type strain had a growth rate of $1.5 \pm 0.1 \mathrm{~mm} \cdot \mathrm{day}^{-1}$ on PDA and $1.5 \pm 0.2 \mathrm{~mm} \cdot$ day $^{-1}$ on PMMG.

\subsection{Screening Fungal Strains for Antagonistic Activity towards C. minus FJT95}

Strains of Trichoderma were screened against C. minus gfp transformant FJT95 in an in vitro screening assay that utilizes GFP expression by the pathogen as an indicator of metabolic activity. The strains tested included some of those previously shown to exhibit antagonistic activity toward D. septosporum such as FBC2, FBC4 and FBC6 [35]. It has been observed that C. minus produces a yellow-colored metabolite (uncharacterized) that is secreted into the medium during growth. The toxicity of this metabolite to other fungi is not known. Therefore, as with D. septosporum, growth measurements of the biocontrol strains were recorded to determine if their growth was inhibited in the presence of C. minus FJT95. The levels of inhibition ranged from $6.3 \%$ to $44.2 \%$, with an average of $17.8 \%$. The strain showing the lowest level of inhibition was FBC4 (Table 1).

Loss of GFP expression by the C. minus FJT95 strain when grown in dual culture was used as an indication of antagonistic activity by potential biocontrol strains as previously described with D. septosporum [35]. FJT95 did not show any loss of GFP fluorescence after growth with FBC11 on PDA medium (Figure 2a,b), suggesting no antagonistic effect of FBC11. Loss of GFP from strain FJT95 was observed when grown with FBC4 on both PDA (Figure 2c,d) and PMMG media (data not shown), suggesting antagonistic activity of FBC4 towards C. minus. While other strains also showed some ability to cause a loss of GFP fluorescence, their antagonist effects appeared to be inconsistent and influenced by the type of media used (summarized in Table 1).

To determine if FJT95 was viable in regions where GFP fluorescence was lost, a small region of the interaction zone containing both the FJT95 and FBC4 mycelia were sub-cultured onto selective media in which only strain FJT95 would grow, as previously described with $D$. septosporum [35]. No growth was observed from the FJT95 plugs taken from colonies overgrown by FBC4 strains, whereas the FJT95 positive control grew on the selective plates, and the C. minus (wild-type) negative control did not grow (data not shown). The results indicated that FBC4 had a fungicidal effect on strain FJT95. 
Table 1. Inhibition of FBC strains by C. minus FJT95 and post-competition green fluorescent protein (GFP) fluorescence of FJT95.

\begin{tabular}{lccccc}
\hline \multirow{2}{*}{$\begin{array}{c}\text { Trichoderma } \\
\text { species and strain }\end{array}$} & \multicolumn{2}{c}{$\begin{array}{c}\text { \% Inhibition of Trichoderma } \\
\text { by C. minus }\end{array}$} & \multicolumn{2}{c}{$\begin{array}{c}\text { Loss of GFP fluorescence in } \\
\text { C. minus }\end{array}$} \\
\cline { 2 - 6 } & & PDA $^{3}$ & PMMG $^{4}$ & PDA & PMMG \\
\hline T. atroviride & FBC2 & $11.9 \pm 7.7$ & $\mathbf{1 2 . 3} \pm \mathbf{8 . 4}$ & + & $+/-$ \\
T. atroviride & FBC4 & $\mathbf{1 3 . 9} \pm \mathbf{3 . 9}$ & $6.3 \pm 5.0$ & - & - \\
T. hamatum & FBC6 & $\mathbf{3 3 . 4} \pm \mathbf{1 0 . 4}$ & $\mathbf{4 4 . 2} \pm \mathbf{3 . 5}$ & - & $+/-$ \\
T. atroviride & FBC9 & $\mathbf{1 0 . 5} \pm \mathbf{7 . 0}$ & $\mathbf{1 3 . 5} \pm \mathbf{4 . 0}$ & - & $+/-$ \\
T. atroviride & FBC10 & $13.0 \pm 0.0$ & $15.5 \pm 4.2$ & + & - \\
T. atroviride & FBC11 & $15.8 \pm 5.6$ & $\mathbf{2 6 . 8} \pm \mathbf{2 . 2}$ & ++ & - \\
T. atroviride & FBC12 & $\mathbf{1 4 . 7} \pm \mathbf{4 . 3}$ & $\mathbf{1 6 . 8} \pm \mathbf{4 . 9}$ & + & - \\
\hline
\end{tabular}

$1 \%$ Inhibition of growth of FBC strains by C. minus (produces uncharacterized metabolites), calculated from radial growth measurements toward and away from C. minus (data not shown). Values are the mean of four replicate assays \pm standard deviation. Text in bold indicates no significant difference $(p \leq 0.05)$ between growth towards and away from C. minus. ${ }^{2}++$ : no loss of GFP fluorescence (indicates no antagonistic activity); +: partial loss GFP fluorescence; -: complete loss of GFP fluorescence (indicates antagonistic activity); +/-: equal number of + and - assays observed. Typical results from four replicate assays. ${ }^{3}$ PDA: Potato dextrose agar (see Section 2.1). ${ }^{4}$ PMMG: Pine minimal medium with glucose (see Section 2.1).

Figure 2. GFP fluorescence of C. minus FJT95 after in vitro interaction with Trichoderma atroviride strains FBC4 and FBC11. (a) FJT95 with FBC11 under visible light; (b) FJT95 with FBC11 under UV light; (c) FJT95 with FBC4 under visible light; (d) FJT95 with FBC4 under UV light; note loss of fluorescence on the left. FBC4 and FBC11 grew towards FJT95 from left hand side of the photographs.
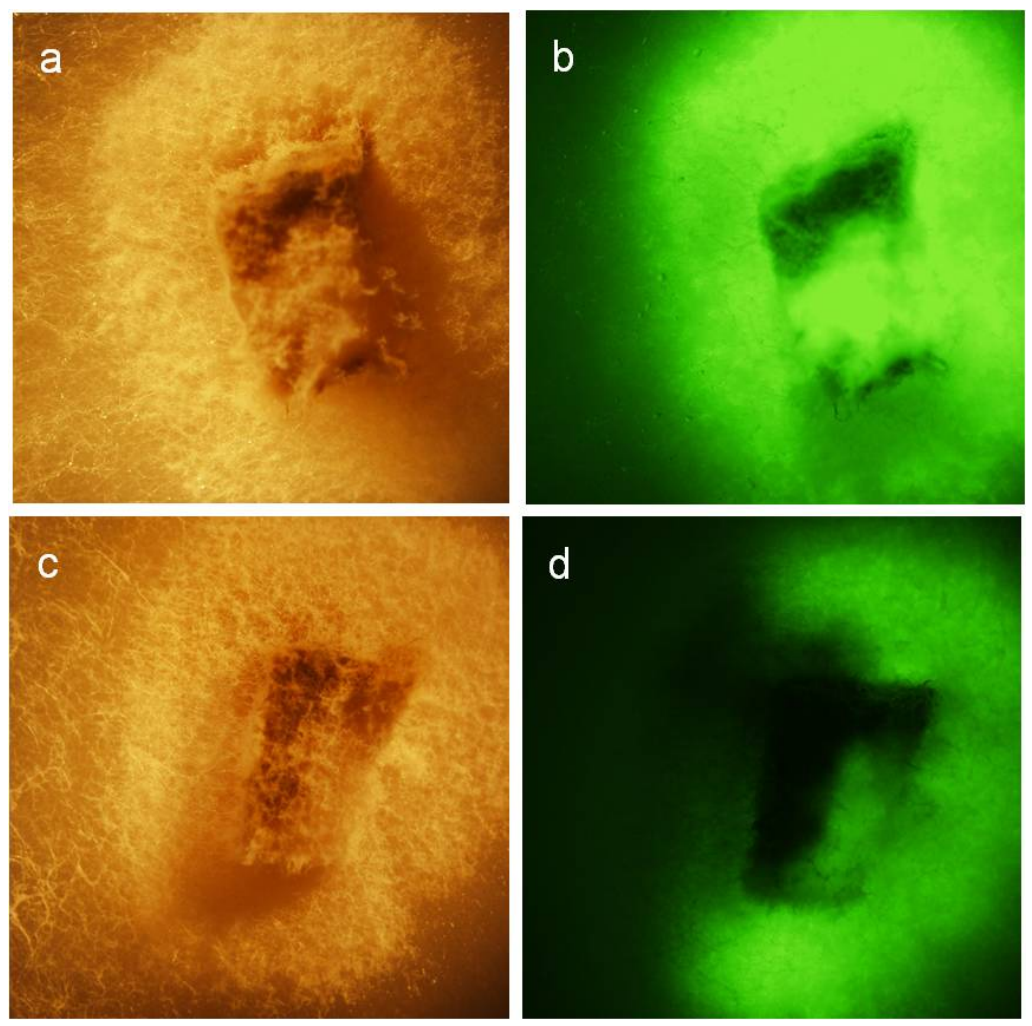


\section{Discussion}

The ability to perform genetic manipulation with plant pathogenic fungi paves the way for studies of complex host-pathogen or pathogen-biocontrol agent interactions. In this study we have shown that C. minus is amenable to transformation, although the transformation efficiency was poor despite obtaining good numbers of protoplasts. Further studies are required to optimize the transformation efficiency. Nevertheless, transformation was achieved and the C. minus GFP-transformant, strain FJT95, did not exhibit any differences to the wild-type strain with respect to growth rate on the two media tested. The GFP-labeled C. minus strain FJT95 was used for further studies to investigate the biocontrol potential of Trichoderma strains.

The use of a previously published method for screening potential biocontrol agents of D. septosporum [35] was applied to C. minus strain FJT95 in this study. This method was previously shown to be effective for $D$. septosporum, a slow-growing fungus that secretes metabolites into the growth medium. These are also characteristics of $C$. minus and the method proved very effective with this organism. The colony morphologies of D. septosporum and C. minus are quite different, the former having raised, dense colonies and the latter more flat and filamentous. Despite this the GFP based-method still provided clear results indicating that the Trichoderma strain that showed greatest antagonistic activity against $C$. minus was also antagonistic toward D. septosporum [35], and suggests that this method could be used to test the biocontrol potential of other fungi.

The results of the screening method, utilizing GFP expression and data from colony measurements, were used to determine which Trichoderma strains showed potential for biocontrol of C. minus. For simplicity, we present data for six strains of T. atroviride and one strain of T. hamatum, although the method was tested using a total of 20 strains including Trichoderma spp (belonging to four species) as well as one strain each of Clonostachys rosea and one strain of Ulocladium sp. Of all the strains tested T. atroviride strain $\mathrm{FBC} 4$ had the greatest antagonistic activity against $C$. minus in vitro, as evidenced by consistent loss of GFP from strain FJT95 on both media. Strain FBC4 also grew well in the presence of $C$. minus as shown by low growth inhibition levels, whilst other strains such as T. hamatum FBC6 were inhibited, leading us to speculate that C. minus produces antifungal metabolites. Interestingly, T. atroviride strain FBC4 also showed a high level of antagonism toward D. septosporum, whereas FBC2 was less effective at reducing GFP expression from C. minus compared to D. septosporum [35]. In addition, loss of GFP expression also correlated with fungicidal activity of the biocontrol strains, as determined by sub-culturing on medium containing hygromycin. Lack of growth on hygromycin by FBC4-challenged C. minus FJT95 (that contained a hygromycin resistance selectable marker gene as well as the $\mathrm{gfp}$ gene), indicated that it had lost viability.

Nursery and forest trials are required to determine if the biocontrol candidates identified in this in vitro study have potential for control of CNC. Because C. minus generally only causes disease on $P$. radiata from an age of approximately three years [2], it would be difficult to perform in planta biocontrol trials with seedlings. However, it may be possible to perform nursery trials with small plants grown from cuttings of trees that are older than three years.

GFP-labeling of plant pathogens opens the door to many techniques for studying their pathogenicity. For example further characterization of the infection process, or elucidating the mechanism involved in its endophytic or latent pathogen lifestyle will be facilitated by use of the GFP-labeled C. minus strain. 
To the best of our knowledge, this is the first time genetic transformation of $C$. minus has been achieved, thus providing a GFP-labeled strain and ability to use this strain to further validate a recently published method for biocontrol screening. In planta testing of potential biocontrol strains identified using this type of approach will provide further screening to elucidate the most promising strains for biocontrol.

\section{Acknowledgments}

RM was supported by funding from The Agricultural and Marketing Development and Research Trust (AGMARDT). Margaret Dick (Scion, New Zealand) is thanked for providing C. minus NZFS3617. Robert Hill (Bio-Protection Research Centre, New Zealand) is thanked for advice on screening strains for biocontrol. Rebecca Ganley and John Bain are thanked for comments on the manuscript. This work was carried out in compliance with the current laws governing genetic experimentation in New Zealand.

\section{Conflict of Interest}

The authors declare no conflict of interest.

\section{References}

1. DiCosmo, F.; Peredo, H.; Minter, D.W. Cyclaneusma gen. nov., Naemacyclus and Lasiostictis, a nomenclatural problem resolved. Eur. J. For. Path. 1983, 13, 206-212.

2. Bulman, L.S.; Gadgil, P.D. Cyclaneusma needle-cast in New Zealand, Forest Research Bulletin No. 222; Forest Research: Rotorua, New Zealand, 2001.

3. Gadgil, P.D. Cyclaneusma (Naemacyclus) needle-cast of Pinus radiata in New Zealand. 1. Biology of Cyclaneusma minus. New Zeal. J. For. Sci. 1984, 14, 179-196.

4. Gernandt, D.S.; Platt, J.L.; Stone, J.K.; Spatafora, J.W.; Holst-Jensen, A.; Hamelin, R.C.; Kohn, L.M. Phylogenetics of Helotiales and Rhytismatales based on partial small subunit nuclear ribosomal DNA sequences. Mycologia 2001, 93, 915-933.

5. Lantz, H.; Johnston, P.R.; Park, D.; Minter, D.W. Molecular phylogeny reveals a core clade of Rhytismatales. Mycologia 2011, 103, 57-74.

6. Kistler, B.R.; Merrill, W. Etiology, symptomology, epidemiology and control of Naemacyclus needle-cast of Scots pine. Phytopathology 1977, 68, 267-271.

7. Merrill, W.; Wenner, N.G. Cyclaneusma needle-cast and needle retention in Scots Pine. Plant Dis. 1996, 80, 294-298.

8. Helander, M.L.; Sieber, T.N.; Petrini, O.; Neuvonen, S. Endophytic fungi in Scots Pine needlesSpatial variation and consequences of simulated acid-rain. Can. J. Bot. 1994, 72, 1108-1113.

9. Kowalski, T. Fungi in living symptomless needles of Pinus sylvestris with respect to some observed disease processes. J. Phytopathol. 1993, 139, 129-145.

10. Sieber, T.N.; Rys, J.; Holdenrieder, O. Mycobiota in symptomless needles of Pinus mugo ssp. uncinata. Mycol. Res. 1999, 103, 306-310.

11. Drenkhan, R.; Hanso, M. Recent invasion of foliage fungi of pines (Pinus spp.) to the Northern Baltics. For. Stud. 2009, 51, 49-64. 
12. Crous, P.W.; Wingfield, M.J.; Swart, W.J. Shoot and needle diseases of Pinus spp. in South Africa. South African For. J. 1990, 60-66.

13. Bulman, L. Quantifying pest impact and spread: Cyclaneusma needle-cast. In Forest Biosecurity and Protection Annual Science Report; Scion: Rotorua, New Zealand, 2009. Available online: http:/www.scionresearch.com/general/science-publications/science-publications/technical-reports/ forest-protection/forest-biosecurity (accessed on 20 November 2011).

14. Gadgil, P.D. Symptoms and pathogenicity. In Cyclaneusma needle-cast in New Zealand, Forest Research Bulletin No. 222; Bulman, L.S., Gadgil, P.D., Eds.; Forest Research: Rotorua, New Zealand, 2001; pp. 2-5.

15. Bulman, L. Scion (New Zealand Forest Research Institute Ltd), Rotorua, New Zealand. Personal Communication, 2011.

16. Dick, M.A.; Somerville, J.G.; Gadgil, P.D. Variability in the fungal population. In Cyclaneusma needle-cast in New Zealand, Forest Research Bulletin No. 222; Bulman, L.S., Gadgil, P.D., Eds.; Forest Research: Rotorua, New Zealand, 2001; pp. 12-19.

17. Glen, M.; Prihatini, I.; Smith, T.; Wardlaw, T.; Mohammed, C. Spring Needlecast in TasmaniaFungal Communities and Environmental Factors. Presented at ACPP APPS 2011: New Frontiers in Plant Pathology for Asia and Oceania, Darwin, Australia, 26-29 April 2011. Available online: http://www.appsnet.org/Publications/Proceedings/APPS\%202011\%20Handbook.pdf (accessed on 20 November 2011).

18. Lorang, J.M.; Tuori, R.P.; Martinez, J.P.; Sawyer, T.L.; Redman, R.S.; Rollins, J.A.; Wolpert, T.J.; Johnson, K.B.; Rodriguez, R.J.; Dickman, M.B.; Ciuffetti, L.M. Green fluorescent protein is lighting up fungal biology. App. Environ. Microbiol. 2001, 67, 1987-1994.

19. Larrainzar, E.; O’Gara, F.; Morrissey, J.P. Applications of autofluorescent proteins for in situ studies in microbial ecology. Annu. Rev. Phytopathol. 2005, 59, 257-277.

20. Lu, Z.X.; Tombolini, R.; Woo, S.; Zeilinger, S.; Lorito, M.; Jansson, J.K. In vivo study of Trichoderma-pathogen-plant interactions, using constitutive and inducible green fluorescent protein reporter systems. Appl. Environ. Microbiol. 2004, 70, 3073-3081.

21. McLean, T.; Fourie, P.H.; McLeod, A. Reporter gene transformation of the trunk disease pathogen Phaeomoniella chlamydospora and biological control agent Trichoderma harzianum. Australas. Plant. Path. 2009, 38, 153-167.

22. Bulman, L.S. Economic impact of Cyclaneusma Needlecast in New Zealand. In Client Report No. 16815; Scion: Rotorua, New Zealand, 2009.

23. Hood, I.A.; Bulman, L.S. Chemical control. In Cyclaneusma Needle-Cast in New Zealand, Forest Research Bulletin No. 222; Bulman, L.S., Gadgil, P.D., Eds.; Forest Research: Rotorua, New Zealand, 2001; pp. 50-54.

24. Watt, M.; Rolando, C.; Palmer, D.; Bulman, L.S. Predicting the severity of Cyclaneusma minus on Pinus radiata in New Zealand. Forest Health News 2011, 217. Available online: http://www.scionresearch.com/general/science-publications/science-publications/science-newsletters/ forest-health-newsletter (accessed on 20 November 2011).

25. Reglinski, T.; Dick, M. Biocontrol of forest nusery pathogens. New Zeal. J. For. Sci. 2005, 50, 19-26. 
26. Valiente, C.; Diaz, K.; Gacitúa, S.; Martinez, M.; Sanfuentes, E. Control of charcoal root rot in Pinus radiata nurseries with antagonistic bacteria. World J. Microb. Biot. 2008, 24, 557-568.

27. Held, B.W.; Thwaites, J.M.; Farrell, R.L.; Blanchette, R.A. Albino strains of Ophiostoma species for biological control of sapstaining fungi. Holzforschung 2003, 57, 237-242.

28. Vanneste, J.L.; Hill, R.A.; Kay, S.J.; Farrell, R.L.; Holland, P.T. Biological control of sapstain fungi with natural products and biological control agents: A review of the work carried out in New Zealand. Mycol. Res. 2002, 106, 228-232.

29. Schoeman, M.W.; Webber, J.F.; Dickinson, D.J. The development of ideas in biological control applied to forest products. Int. Biodeter. Biodegr. 1999, 43, 109-123.

30. Reglinski, T.; Rodenburg, N.; Taylor, J.T.; Northcott, G.L.; Chee, A.A.; Spiers, T.M.; Hill, R.A. Trichoderma atroviride promotes growth and enhances systemic resistance to Diplodia pinea in radiata pine (Pinus radiata) seedlings. For. Pathol. 2012, 42, 75-78.

31. Hill, R.A.; Paderes, D.E.; Wigley, P.J.; Broadwell, A.H. Growth of Pinus radiata seedlings in the nursery with novel microbial formulations. N. Z. Plant Protect. 2007, 60, 305.

32. Hill, R.A.; Stewart, A.; Hohmann, P.; Braithwaite, M.; Clouston, A.; Minchin, R. Enhancing growth and health of Pinus radiata in New Zealand and Acacia mangium in Malaysia with selected Trichoderma isolates. In Proceedings of the 11th International workshop on Trichoderma and Gliocladium, Haifa, Israel, 13 October 2010.

33. Paderes, D.E.; Hill, R.A.; Wang, W.-Y.; Stewart, A. Development of a bio-protection system for Pinus radiata with Trichoderma (ArborGuard ${ }^{\mathrm{TM}}$ ). In Proceedings of the 4th Australasian Soilborne Diseases Symposium, Queenstown, New Zealand, 3-6 September 2006.

34. Moraga-Suazo, P.; Opazo, A.; Zaldúa, S.; González, G.; Sanfuentes, E. Evaluation of Trichoderma spp. and Clonostachys spp. strains to control Fusarium circinatum in Pinus radiata seedlings. Chil. J. Agri. Res. 2011, 71, 412-417.

35. McDougal, R.; Yang, S.; Schwelm, A.; Stewart, A.; Bradshaw, R. A novel GFP-based approach for screening biocontrol microorganisms in vitro against Dothistroma septosporum. J. Microbiol. Meth. 2011, 87, 32-37.

36. Bullock, W.O.; Fernandez, J.M.; Short, J.M. XL1-Blue-A high efficiency plasmid transforming recA Escherichia coli strain with beta-galactosidase selection. Biotechniques. 1987, 5, 376-378.

37. Bradshaw, R.E.; Ganley, R.J.; Jones, W.T.; Dyer, P.S. High levels of dothistromin toxin produced by the forest pathogen Dothistroma pini. Mycol. Res. 2000, 104, 325-332.

38. Sambrook, J.; Fritsch, E.F.; Maniatis, T. Molecular Cloning: A Laboratory Manual, 2nd ed.; Cold Spring Harbour Laboratory Press: New York, NY, USA, 1989.

39. Bradshaw, R.E.; Bidlake, A.; Forester, N.; Scott, D.B. Transformation of the fungal forest pathogen Dothistroma pini to hygromycin resistance. Mycol. Res. 1997, 101, 1247-1250.

40. Doyle, J.J.; Doyle, J.L. A rapid DNA isolation procedure for small quantities of fresh leaf tissue. Phytochem. Bull. 1987, 19, 11-15.

(C) 2012 by the authors; licensee MDPI, Basel, Switzerland. This article is an open access article distributed under the terms and conditions of the Creative Commons Attribution license (http://creativecommons.org/licenses/by/3.0/). 